\title{
Application of Infiltrative Moral Quality Education In The Cultivation Of Journalism Talents In Colleges and Universities
}

\author{
Xu Hongyan \\ ${ }^{1}$ College of Liberal Arts, Bohai University, Jinzhou, P.R.China \\ ${ }^{2}$ Doctoral student of journalism of Renmin University of China \\ Beijing, P.R.China \\ Tujia1980@126.com
}

Key words: infiltrative education, moral quality, journalism talents

\begin{abstract}
In the moral education of journalism talents in universities, infiltrative education can play an active role. The methods of infiltration moral quality education are various, and its contents are flexible, furthermore, it has good imperceptible education effect, it will enable educators to have a stable and lasting educational effect in psychology, attitude and ideology. Therefore, it can play an active role in moral education of News Talents in Colleges and universities. Specifically, we can carry out the infiltration moral education of News Talents through five aspects: permeating moral quality education in public elective courses, developing permeable moral quality education in professional courses teaching; closely combining the infiltrative moral education and practical activities; carrying out permeable education effectively by using micro-blog and WeChat platform; developing moral quality education in school management effectively.
\end{abstract}

\section{Introduction}

Journalists are an important force in Ideological work, and their moral standards have a crucial impact on the level and effectiveness of journalism. Therefore, every country attaches great importance to the cultivation of journalistic talents' moral quality. In the moral education of journalism talents in universities, infiltrative education can play an active role.

\section{The infiltrative moral quality education: moistening things silently}

"Infiltrative Education, it means that the educator consciously creates a certain living environment and cultural atmosphere around the educated in accordance with the predetermined educational contents, programs and educational purposes, and with the help of relevant carriers, to guide the educator to feel and appreciate them, then consciously or unconsciously develop the views on world the outlook on life and values advocated by educators. As a result, the educated can get the influence of the soul, the edification of sentiment and philosophical enlightenment, so that the ideological works of the educated can be optimized." [1]

The concept of infiltrative moral education has a long history. In ancient Greece, Socrates advocated moral education for children mainly through discussion and organization of activities. Platon also believes that moral education can't rely solely on the education of knowledge theory. In modern times, the concrete theory of infiltration education has been further developed and perfected. Some educationists and psychologists in the West advocated that student's knowledge and abilities should be developed and improved imperceptibly through independent and conscious rational and practical activities, and opposed "inculcating students with theories and principles simply."

In the early 20th century, American educator Dewey believed that "the only real education comes from the stimulation of children's abilities by the needs of their social environment." Thus, informal education is introduced into curriculum practice. Moral education is carried out by integrating children with professional teaching, participating in social life, and working to solve practical problems. In 1968, the concept of "hidden curriculum" by American scholar Jackson made the outline of infiltrative education clear. "Western countries are also paying more and more 
attention to the experience of infiltrative education, political education and moral education in Western countries has achieved good results, in the concealment, indirect, ingenious and artistic infiltrative education." [2]

\section{The advantages of infiltrative moral literacy education}

Infiltrative education, which affects the educated unconsciously through indirect and unconscious implicit education activities, it is more in line with the current needs of young people in pursuit of individualized, autonomous and practical education, and can make up for the shortcomings of other forms of education, especially positive indoctrination. Which has great advantages in enhancing the effect of moral education.

Firstly, the intention of penetrating education is relatively concealed. It gradually penetrates the educational purpose and intention in the daily learning process, living environment and social practice activities of the educated, thus influences the educational object imperceptibly. Secondly, its educational methods are diverse and flexible. Educational content is hidden in the environment, media, activities, culture, management and other factors, which can integrate various educational measures and can form a joint educational effort. Thirdly, on the psychological level, the educated are free and equal and emotionally cheerful. With the help of effective carriers in the educational environment, educational contents and concepts are easily and happily accepted by the educatees in a relatively concealed and flexible form without their consciousness. In this process, the educatees will change their psychology, emotions, attitudes, thoughts and other aspects and produce a stable and lasting effect.

\section{The way to achieving the infiltrative moral quality education}

\subsection{Permeating moral qualities in public elective courses}

In order to expand the subject structure and knowledge literacy of College students, colleges and universities have set up a wealth of public elective courses for students. Many courses such as philosophy, literature, art, history, etc. play a very important role in the formation and cultivation of human morality. Therefore, we should attach importance to the role of "carrier" and "infiltration" of Humanities and Social Sciences Classroom teaching, so that these courses can become the "carrier" or "carrier" of moral "infiltration". By offering courses such as literature, art, music, history, philosophy, sociology, culture, politics, law and so on, students can acquire a great deal of knowledge of Humanities and Social Sciences, and at the same time absorb certain moral knowledge and ideas, such as love, responsibility, justice, fairness, trustworthiness, conscience and so on. Patriotism, humanitarianism, environmental awareness, scientific spirit, global awareness, etc. should become the important contents of permeable moral education.

\subsection{Developing permeable moral education in professional courses teaching}

Professional courses are the major subjects of college students. As the most important learning contents of students, professional courses can play a more significant role in strengthening moral education infiltration. It mainly includes three main ways: imparting knowledge, discussing topics and carrying out infiltrating moral education in practical training. Taking the course of Media Ethics and Regulations as an example, when it comes to the knowledge of "respecting judicial independence and human rights, opposing media trial", teacher carries out permeable moral education through these three ways.

First of all, teacher will introduce the important characteristics of media trial-----the media transcend the judicial process to prejudge the merits of the case, make the conclusion that those involved in a case may be win or lose the lawsuit, and prejudge the nature conviction and quantitative punishment for the involved persons. Then the teacher will combine the corresponding cases to make the students understand that "excessive media justice" will form an atmosphere of public opinion enough to affect the court's independent trial, affect judicial independence, violate 
the human rights of the persons involved, and permeate the spirit of the rule of law of modern citizens.

Afterwards, on the basis of theoretical lectures, teacher arranges students to prepare for debates related to media trials. In the training activities of the teacher-student discussion and debate contest, students collect multi-dimensional materials for relevant cases actively, conduct legal analysis and media ethics thinking, they can deeply realize the negative impact of media trial phenomenon, and try to explore the ways to maintain a balance between news reporting and judicial trial. In this process, the socialist core values of "freedom, equality, justice and the rule of law" have been more deeply rooted in the hearts of the people.

\subsection{Combining the infiltrative moral education and practical activities closely}

With own educational purposes, rich campus cultural activities and diverse social practices are beneficial supplements to the school curriculum. Through lively moral education activities, students can be nurtured, infected and cultivated, and then imperceptibly accept the educational intentions of educators, finally their self-awareness, self-feeling, self-understanding, self-education and self-growth could be promoted. For example, by the aid of a variety of drama performances, art evenings and other campus cultural activities, college students are easy to accept the correct values, which can be easily integrated into students' ideology through these carriers and internalized into their actions because of the relaxed and harmonious atmosphere of campus cultural activities.

\subsection{Using new media platform to develop infiltrative education}

Nowadays, college students are the new force of using the platform of micro-blog and WeChat. They have taken micro-blog and $\mathrm{WeChat}$ as the important platform to transmit and acquire information, communicate emotion and spread ideas effectively in their daily life. Micro-blog and WeChat, with the characteristics of fast updating speed, large amount of information, strong carrying capacity, deep permeability and strong interaction, become the ideal carriers of socialist core values. They can effectively use multimedia technology to transmit moral education information, and greatly enhance the attraction, infectivity and influence of penetrating education. Specifically, we can open the college's official account on Weibo and the Official WeChat public address, to understand the real wishes and realistic demands of students, and to solve the students' problems. College students are encouraged to pay close attention to student affairs involving their vital interests through official account on Weibo and the Official WeChat public address, so that they can feel the close relationship between themselves and the development of the school. For teachers, micro-blogging and micro-messaging platforms also expand the channels for educating, increase the opportunity to communicate with students after school hours, and play the role of "answering questions and problems".

\section{Acknowledgement}

This research was financially supported by Bohai University's practical (progressive) project "Strategic research on strengthening the public opinion governance of the province in the era of big data" , the research topic of economic and social development in Liaoning Province in 2019, "established a comprehensive network management system and created a clear network space study" (No. 20191slktyb-033), and the special topic of "Xi Jinping's New Era of Socialism with Chinese Characteristics" in Bohai University "Study on enhancing and improving the network ideology work of the university in the new era ".

\section{References}

[1] Yang Zaiyan. On Moral Education and Moral Education Infiltration [J].Journal of Guangxi University for Nationalities (Philosophy and Social Sciences Edition), 1998 (03): 78 
[2] Li Fangyuan. Research on the Infiltrative Education in the Process of Political Socialization of American Youth [D]. Harbin Engineering University. Master's Dissertation. 2011:14 